\title{
Simulation and experimental response of four-bar mechanism with tolerance stack
}

\author{
Chandrashekhar A. Akhadkar ${ }^{*}$, Ashish B. Deoghare ${ }^{2}$ and Adwait M. Vaidya ${ }^{3}$ \\ ${ }^{1}$ Research Scholar of Mechanical Engineering Department, \\ G. H. Raisoni College of Engineering, Nagpur, Maharashtra, India \\ Phone: +91-83081 59090 \\ *Email: c.akhadkar@gmail.com \\ ${ }^{2}$ Faculty of Mechanical Engineering, National Institute of Technology, \\ Silchar, Assam, India. \\ ${ }^{3}$ Faculty of Mechanical Engineering, Gangamai College of Engineering, \\ Nagaon, Dhule, Maharashtra, India.
}

\begin{abstract}
An Equivalent Contact Stiffness (ECS) approach is proposed in this article to estimate the precise contact parameters for a revolute joint. Estimated contact parameters are used as input variables for the MBD simulation of a four-bar mechanism with tolerance stack. Simulations were carried out using Impact Force Method (IFM) and Restitution Method (RM) in MSC ADAMS. An experimental setup of the four-bar mechanism is developed with a unique feature to measure the angular velocity of the follower with respect to the crank position. The effect of tolerance stack on the angular velocity of the follower is investigated experimentally to validate the MBD simulation. The angular velocity of coupler and rocker is increased by $15.69 \%$ and $27 \%$ respectively due to tolerance stack. MBD analysis using the ECS approach provides accurate and reliable results in absence of experimental contact data. This work shall facilitate the designers to simulate the actual behaviour of the mechanism prior to prototype.
\end{abstract}

Keywords: Tolerance stack; equivalent contact stiffness; multibody dynamic analysis; penetration; four-bar mechanism.

\section{INTRODUCTION}

Kinematic and dynamic simulation of a mechanism is often simplified with the assumptions like ideal kinematic joints, perfect shape, and size of the bodies in connection. However, the dimensional variations are always associated with each interconnected body due to the limitations of manufacturing processes. An accumulated dimensional variation allowed by the individual dimension is termed as tolerance stack. Variations in the link dimension due to the tolerance [01] and clearance in the joints are the contributors of the tolerance stack. The clearances in the kinematic joints are required for the relative motion between the mechanism links. It is desirable to have a minimal clearance in the joints for the robust performance of the mechanism. The tolerance on link lengths and clearances in joints alters the response of the multibody mechanical system. Therefore, it is necessary to study the 
combined effect of tolerance on link lengths and joint clearance on the dynamic behaviour of a mechanism. As of now, researchers focused on the investigations on the behaviour of four-bar mechanism with clearance in the single or multiple revolute joints and estimation of the path deviation and kinematic simulation[02-05].

A MBD approach enables the motion analysis of mechanism under the influence of forces. Connections between the mechanism links can be modeled as kinematic constraints (joints). Modeling of contacts of the joints influences the MBD simulation of the mechanism $[05,06]$. Koshy et. al. [07] used normal contact force to simulate the clearance in the kinematic joint. The normal contact force is a continuous function of the penetration between the contacting bodies. The authors claimed that MBD is the computationally simple and efficient method, which is suitable for the contact between the bodies. The Hertz's contact theory [08-11] is the basis for estimation of contact force. However, it does not account for the energy dissipated during the impact of the colliding bodies. Therefore, it is used along with dissipative term (damping) to evaluate joint forces. Flores et. al. [13] used the contact force model proposed by Lankarani and Nikravesh [14]. They have considered revolute joints as colliding bodies to study the effect of radial clearance in terms of acceleration amplification factor. The current study is focused on the MBD simulation of a four-bar mechanism with tolerance on link length and clearance in joints. The research work [07-14] shows that inclusion of the damping terms into a contact model improves mechanism response. Pereira et. al. [15] observed variation in the penetration values due to lower contact forces between contacts of cylindrical surfaces of revolute joints. The contact parameters (stiffness and deformation) were estimated using the Hertz's contact theory for the two spherical bodies is in contact.

Determination of accurate combined stiffness and depth of penetration of joint elements, accurate damping coefficient are significant for the nonlinear contact MBD simulation of the mechanism. The accurate combined stiffness, depth of penetration and damping are based on the geometries and materials of joint elements in contact, which are determined by experimentation, it is a tedious and time consuming process. In view of above, an Equivalent Contact Stiffness (ECS) approach is proposed for estimation of contact parameters for revolute joints in present work. Contact parameters are calculated by the Hertz's contact theory of contact of two spherical bodies. However, in revolute joint two cylindrical surfaces are in contact therefore, contact parameters are calculated by the Hertz's contact theory of contact of two cylindrical bodies for comparison. Proposed ECS approach is used for the estimation of contact parameters, which are used as input variables for contact MBD simulation of a selected mechanism. An experimental setup was developed and fabricated to measure the angular speed mechanism links with respect to the crank position. Experimental verification of angular speed of the rocker is carried out. The work emphasised to understand the effect on joint forces due to the tolerance stack using MSC ADAMS (Version 12.0) software.

The present study is on nonlinear contact MBD simulation of a four-bar (crankrocker) mechanism. The dimensional tolerance on lengths of mechanism links with respect to the coarse tolerance grade as per IS 2102 (Part 1):1993 [16] is targeted, together with radial clearance for medium running fit (H8g7) of $0.021 \mathrm{~mm}$ in four revolute joints. MSC ADAMS supports two algorithms namely, IFM and RM for contact MBD simulation. Both the methods are based on the concept of penalty regularisation. Penalty regularisation is a technique of compliant approach; it is a reaction to the normal force at the point of contact. 
Penalty regularisation is a simple approach and it does not require additional equations and variables, and appropriate in active and inactive conditions of unidirectional constraints. However, the accurate setting of contact parameter is a challenging task. [17, 23]. The accuracy of MBD simulation depends on the precision of contact parameters. The contact parameters are generally investigated by performing several experiments. Contact parameters are based on the geometry, materials in contact, surface finish, and normal contact force. To perform experiments manufacturing of different sets of spheres or cylinders with required design dimensions, surface finish, and materials in contact are essential. In addition, the normal contact force is essential for experimentation. Often it is unknown for revolute joint and it is dependent on the input speed/torque of the mechanism. Investigation of contact parameters by performing several experiments in the laboratory is quite a time consuming task. In absence of experimental contact data combined contact stiffness, depth of penetration and damping coefficient are assumed initially for nonlinear contact MBD simulation using ADAMS, and iterations are carried out to achieve required motion. The proposed ECS approach provides accurate combined stiffness and depth of penetration in absence of experimental contact data. Therefore, conventional iterative MBD simulations can be avoided. MBD simulation using ECS approach has the potential to obtain swift solutions. It is useful in defect investigation of a mechanism. The nonlinear MBD analysis using ECS approach gives behaviour of actual mechanism at the design stage before prototype or manufacturing.

\section{METHODS OF NONLINEAR CONTACT MBD SIMULATION}

IFM and RM are based on the assumption that the contacting bodies are locally deformable bodies. A contact force is a continuous function of the penetration between them. In IFM, the normal force during impact is a spring force derived from Hertz's contact theory. Dissipation of energy during the impact is accounted by dissipative term damping. The stiffness, depth of penetration, a coefficient of damping and force exponent are the four inputs required by IFM. In RM, contact force is computed from penalty parameter and coefficient of restitution (COR). The penalty parameter enforces unilateral constraint and COR controls the dissipation of energy at the contact. RM is suitable for calculating normal force at the contact when the energy loss during impact is known.

The conditions immediately before and after the impact are simulated with the IFM. The contact stiffness plays an important role to maintain the continuous contact between the two colliding bodies $[18,27]$. The accuracy of MBD analysis is reliant on the precise contact parameters. The contact parameters are generally investigated by performing experiments. In absence of experimental contact data, they are assumed initially. Contact parameters are dependent on the geometries and materials in contact. For steel-to-steel spherical body contact, contact stiffness and coefficient of restitution are $1.5 \times 10^{8} \mathrm{~N} / \mathrm{mm}$ and 0.8 respectively [19]. Investigation of contact parameters by performing several tests in the laboratory is quite a hard task. The deformations of the contacting surfaces and contact area are dependent on the geometries, materials in contact, surface finish, and normal contact force. Manufacturing of different sets of spheres or cylinders with required design dimensions, surface finish, and materials in contact are essential. In addition, the normal contact force is essential for experimentation. It is generally unknown for revolute joint and it is dependent on the input 
speed/torque of the mechanism. In absence of experimental contact data, instead of using assumed contact parameters for MBD analysis, a new ECS approach is proposed. It is based on Hertz's contact theory.

\section{Impact Force Method (IFM)}

Modelling of dry revolute joint with clearance is divided into two parts:

i. The formation of the joint having relative motion between the connected links is described by a kinematic part exclusively.

ii. A contact force is illustrated by unilateral contact condition.

The normal contact force $\left(F_{n}\right)$ is calculated using the material stiffness. The displacement of the contacting bodies in terms of dependent viscous damping term is estimated by introducing the damping term in the impact force Eq. (1) $[17,18]$.

$$
F n=k \delta^{e}
$$

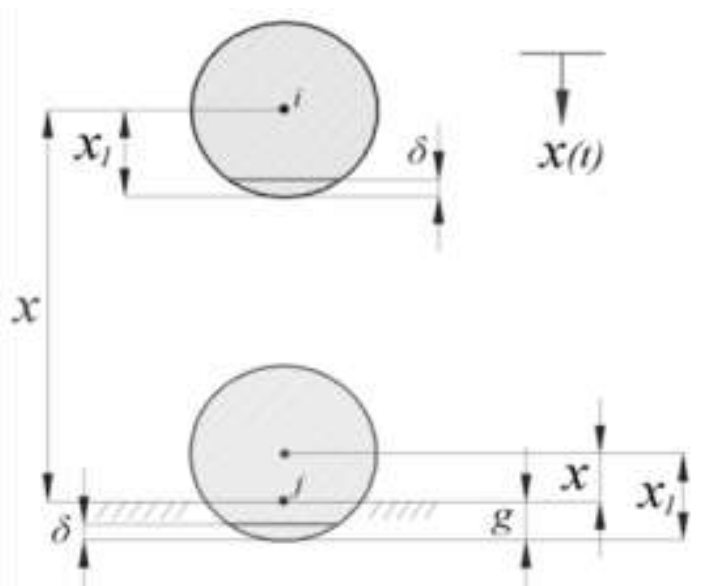

Figure 1. Illustration of impact function

The impact function is illustrated in Figure 1. The IMPACT function has seven arguments as given below,

$$
I M P A C T=\left(x, \dot{x}, x_{1}, k, e, c_{\max }, \delta\right)
$$

Where, $x$ is a distance variable used to compute impact function, $\dot{x}$ derivative of $x$ function with respect to time, $x_{1}$ is a positive real variable specifies free length of $x . k$ is the material stiffness, and $e$ is the positive real value indicating the force exponent. $\delta$ is a positive real value specifying the boundary of penetration to apply the maximum damping coefficient $c_{\text {max }}, g$ is the gap function represented by $\left(x_{1}-x\right)[17,18]$. Therefore, the general form of the impact force function is given by Eq. (3),

$$
F_{n}=k\left(x_{1}-x\right)^{e}+c_{\max } \dot{x} \times \operatorname{Step}\left(x, x_{1}-\delta, x_{1}\right) \dot{x}: x<x_{1}
$$

When, $x>x_{1}$, no mutual surface penetration occurs and the normal force is zero (gap function, $g=0$ ). $x<x_{1}$, gap function $\mathrm{g}$ occurs at the end closer to the $\mathrm{j}$ body, and the force is $>0$. Also, 
when $g<\delta$, the instantaneous damping coefficient is a cubic step function of the gap function $g$. When $g>\delta$, the instantaneous damping coefficient is $c_{\max }$. The impact activates when the distance between the two objects is smaller than the free length of $x$. Therefore, the force becomes non-zero and consists of two components an exponential spring force and a damping force that follows a step function.

The IFM is numerically efficient and will result in faster simulations. In addition, it provides greater control over the contact behaviour due to the inclusion of damping, and force exponent. Therefore, IFM is used for the study because it provides accurate and reliable analysis results $[17,18]$. The relative motion of the links takes place after the mutual interaction is the impact; whereas interaction without relative motion is contact phenomenon. The impact forces are acting momentarily, however, it causes a significant change in the velocity of bodies in contact and thus in the momentum.

\section{Restitution method (RM)}

Contact force is estimated from penalty parameter and coefficient of restitution. The penalty parameter enforces the unilateral constraint and the coefficient of restitution controls the dissipation of energy at the contact. The COR defines a continuum between perfectly elastic $(\mathrm{COR}=1)$ and perfectly inelastic collision $(\mathrm{COR}=0)[18]$.

The difference between both the limits implies elastic and inelastic collision with conservation and non-conservation of kinetic energy respectively. In a perfectly inelastic collision, the reduction of kinetic energy is equals to the total kinetic energy before the collision in a center-of-momentum frame. Although the behaviour of kinetic energy is different in these cases, however after collisions the total momentum is conserved. For simple collisions the object velocities can be calculated with the conservation of momentum and the definition of COR:

$$
\begin{gathered}
C O R=\frac{v_{b}-v_{a}}{u_{a}-u_{b}} \\
m_{a} u_{a}+m_{b} u_{b}=m_{a} v_{a}+m_{b} v_{b}
\end{gathered}
$$

Where, $m_{a}, m_{b}$ and $v_{a}, v_{b}$ are the masses and velocities of the objects in contact. From Eq. (6) and Eq.(7) the velocities $v_{a}$ and $v_{b}$ are derived,

$$
\begin{aligned}
& v_{a}=\frac{m_{a} u_{a}+m_{b} u_{b}+m_{b} \operatorname{COR}\left(u_{b}-u_{a}\right)}{m_{a}+m_{b}} \\
& v_{b}=\frac{m_{a} u_{a}+m_{b} u_{b}+m_{a} \operatorname{COR}\left(u_{a}-u_{b}\right)}{m_{a}+m_{b}}
\end{aligned}
$$

In RM the normal contact force is calculated using a penalty parameter, which is similar to a stiffness parameter. A small value of normal contact force will result in violation of impenetrability constraint i.e. there should be no negative gap between objects therefore, leads to inaccurate results. However, a large penalty value ensures that the penetration of 
geometry into another will be small, since large values will cause numerical integration difficulties. The function for the normal force associated with the RM is given by Eq. (8).

$$
F n=p(\varepsilon-1) \dot{x}
$$

In which $p$ is the penalty parameter, $\epsilon$ is COR and $\dot{x}$ is the time derivative of gap $(x), \dot{x}=$ $v_{a}-v_{b}$, depending on the object order. RM is a method for calculating the normal force when the energy loss during a collision is known [17]. Therefore, for the estimation of accurate penalty parameter we proposed ECS approach.

\section{EQUIVALENT CONTACT STIFFNESS (ECS) APPROACH}

The ECS approach is proposed for estimation of contact parameters for a mechanism consisting of revolute joints. Revolute joint is a cylindrical pair of bearing and pin having line contact ideally. Therefore, the contact parameters are estimated by the Hertz's equations for cylindrical contact. However, due to the clearance in the revolute joint, the occurrence of line contact between the cylindrical pair is minimal. The position of contact changes to point contact (one point, two points, three points or four point contact) as shown in Figure 2. Thus, contact parameters are also estimated by the Hertz's equations for spherical sphere.

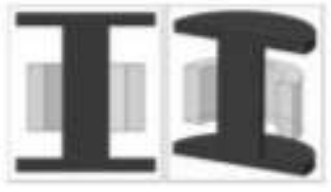

(a)

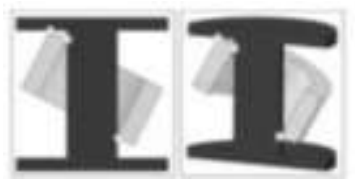

(d)

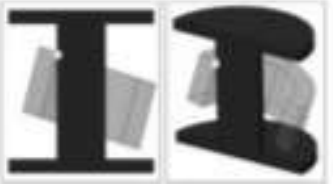

(b)

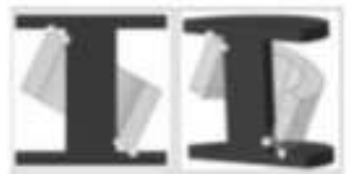

(e)

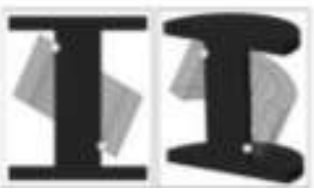

(c)

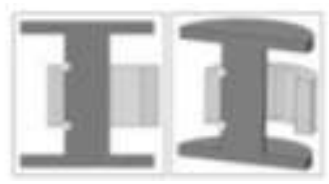

(f)

Figure 2. Positions of contact for revolute joint with clearance (a) No Contact (b) One point contact with pin (c) Two point contact with pin (d) Three point contact (two with pin and one with flange) (e) Four point contact (two with pin and two with flange) (f) Two-point line Contact.

The advantage of the proposed approach is that the trial substitution of contact parameters is eliminated. The stiffness of the two bodies are in contact is depends on their material properties (Poisson's ratio and modulus of elasticity). Contact of two spherical and cylindrical bodies is shown in Figure 3. 


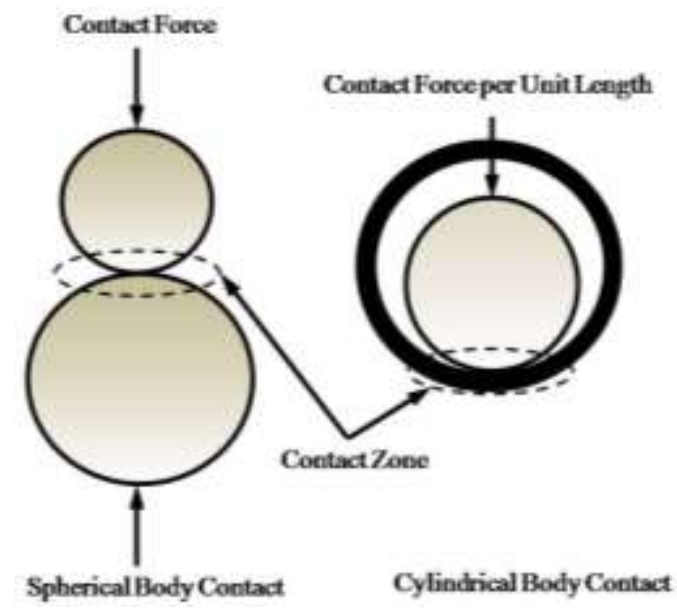

Figure 3. Spherical and cylindrical body contact.

Contact stiffness of two spherical bodies in contact is calculated by the Eq. (9) [11].

$$
K=a E^{*}
$$

Where, $K$ is the combined stiffness of contacting bodies, $a$ is the Hertz's contact radius and $E^{*}$ is the combined young's modulus of the contacting bodies. Depth of penetration of two spherical bodies in contact is calculated by Eq. (10)

$$
\delta=\frac{a^{2}}{R}\left[1-\frac{2}{3}\left(\frac{a_{0}}{a}\right)^{\frac{3}{2}}\right]
$$

Where, $R$ is the combined radius of curvature and $a_{0}$ is the initial contact radius. Similarly, the equivalent radii of two parallel cylinders are in contact is estimated with the Hertz's contact equation. $P$ is the line load (load per unit length of contact) rather than the actual load. In case of mutual approach the penetration depth given by Eq. (11),

$$
\delta=\frac{p}{\pi E^{*}}\left\{\left[\sum_{i=1}^{2} \ln \left(\frac{4 d_{i}}{l}\right)\right]-1\right\}
$$

Where, $d_{i}$ is the internal diameter of cylinder, $l$ is length of cylinder and $\mathrm{b}$ is half width of contact. Equivalent contact stiffness between the contacting materials is given by Eq. (12)

$$
K=\frac{\pi l E^{*}}{\left\{\left[\sum_{i=1}^{2} \ln \left(\frac{4 d_{i}}{b}\right)\right]-2\right\}}
$$

An approach for estimation of contact parameters is as follows: 
a) Angular acceleration of the links of a nominal crank-rocker mechanism is calculated for one cycle by analytical or MBD analysis method. Highest tangential force in cycle acting on the joints is calculated from the Eq. (13). The tangential force leads to contact/collide the pin in the bearing. Therefore, the applied normal force at the contact of two bodies must be equal to the tangential force. Here, $n$ represents the number of joints in the mechanism.

$$
F_{\max }^{t}=\max \left|\alpha_{n_{i}} r_{n} m_{n}\right|_{i=0,2 \pi}
$$

Where, $F_{\text {max }}^{t}$ is the highest tangential driving force at the joint, $\alpha$ is the acceleration of corresponding link, $r$ and $m$ are radius and mass of the pin.

b) The equivalent stiffness and depth of penetration of the pair of the colliding materials are calculated with Hertz's contact equations. For spherical body contact, it is calculated by Eq. (9) and Eq. (10) respectively and for cylindrical body contact; it is calculated by Eq. (12) and Eq. (11) respectively as stated below. The estimated highest tangential force in a cycle is taken as the contact pressure at the point of contact to evaluate the equivalent stiffness.

c) The damping coefficient is considered as 0.01 of the equivalent contact stiffness.

\section{MBD ANALYSIS OF CRANK-ROCKER MECHANISM}

The effect of tolerance stack on the performance characteristics such as velocity, acceleration, and joint force of a mechanism is investigated.

\section{Linkage Parameters of Crank-Rocker Mechanism}

The linkage parameters of crank-rocker mechanism [20] and material properties of steel are given in Table 1. Clearance in the revolute joints is maintained as per the medium running fit $\mathrm{H} 8 \mathrm{~g} 7$. The minimal radial clearance required in the joint for the mobility of the mechanism is 0.01 to $0.02 \mathrm{~mm}$ for the basic size of $25 \mathrm{~mm}$ [21]. Use of the coarse grade tolerance gives more flexibility in component assemblage and economical manufacturing. Input (crank) speed of $20.94 \mathrm{rad} / \mathrm{s}$ (200 RPM) is considered for MBD simulations and experimentations. Multibody dynamic simulation of the four-bar mechanism with clearance in four revolute joints and tolerance on the link lengths is performed using following six methods and validated with experimental results. 
Table 1. Linkage parameters

\begin{tabular}{|c|c|c|c|c|c|c|}
\hline \multirow[b]{2}{*}{ Component } & \multirow[b]{2}{*}{$\begin{array}{l}\text { Link } \\
\text { Length } \\
\text { (mm) }\end{array}$} & \multirow{2}{*}{$\begin{array}{c}\text { Cross } \\
\text { Section of } \\
\text { Link } \\
(\mathrm{mm}) \\
\end{array}$} & \multicolumn{3}{|c|}{ Material Properties } & \multirow[b]{2}{*}{$\begin{array}{l}\text { Mass } \\
(\mathrm{kg})\end{array}$} \\
\hline & & & $\begin{array}{l}\text { Density, } \\
\rho\left(\mathrm{kg} / \mathrm{m}^{3}\right)\end{array}$ & $\begin{array}{l}\text { Poisson's } \\
\text { Ratio, v }\end{array}$ & $\begin{array}{l}\text { Young's } \\
\text { Modulus, E } \\
\left(\mathrm{N} / \mathrm{mm}^{2}\right)\end{array}$ & \\
\hline Fixed Link & $108^{ \pm 0.8}$ & $20 \times 35$ & & & & 0.41 \\
\hline Crank & $279.4^{ \pm 1.2}$ & $10 \times 22$ & & & & 0.14 \\
\hline Coupler & $270.5^{ \pm 1.2}$ & $10 \times 22$ & & & & 0.26 \\
\hline Rocker & $270.5^{ \pm 1.2}$ & $10 \times 22$ & 7801 & 0.29 & $2.07 \times 10^{5}$ & 0.31 \\
\hline Bearing & $10^{+0.022}$ & --- & & & & --- \\
\hline Pin & $\varnothing 10^{-0.005}-0.02$ & $\begin{array}{l}\emptyset 10 \times 20 \\
\varnothing 10 \times 30\end{array}$ & & & & 0.02 \\
\hline
\end{tabular}

MBD analysis methods and their significance are given in Table 2.

Table 2. MBD Simulation Methods.

\begin{tabular}{|c|c|c|}
\hline SI No. & Simulation Method & Description \\
\hline 1 & $\begin{array}{l}\text { Conventional } \\
\text { approach by IFM }\end{array}$ & $\begin{array}{l}\text { Contact stiffness, depth of penetration, damping, and } \\
\text { force exponent }(e) \text { are the input variables required for } \\
\text { the simulation. } \\
\text { - It is an iterative method provides approximate results. }\end{array}$ \\
\hline 2 & $\mathrm{RM}$ & $\begin{array}{l}\text { Penalty regularisation parameter and coefficient of } \\
\text { restitution (COR) are the input variables required for } \\
\text { the simulation. } \\
\text { - It is as well an iterative method provides approximate } \\
\text { results. }\end{array}$ \\
\hline 3 & $\begin{array}{l}\text { ECS approach by IFM } \\
\text { - Cylindrical contact }\end{array}$ & $\begin{array}{l}\text { Contact stiffness, depth of penetration, damping, and } \\
\text { force exponent }(e) \text { are the input variables required } \\
\text { for the simulation. } \\
\text { - Input variables are determined by ECS approach } \\
\text { considering cylindrical bodies in contact }\end{array}$ \\
\hline 4 & $\begin{array}{l}\text { ECS approach by RM } \\
\text { - Cylindrical contact }\end{array}$ & $\begin{array}{l}\text { Penalty regularisation parameter and coefficient of } \\
\text { restitution (COR) are the input variables required for } \\
\text { the simulation. } \\
\text { - Input variables are determined by ECS approach } \\
\text { considering cylindrical bodies in contact. }\end{array}$ \\
\hline 5 & $\begin{array}{l}\text { ECS approach by IFM } \\
\text { - Spherical contact }\end{array}$ & $\begin{array}{l}\text { Contact stiffness, depth of penetration, damping, and } \\
\text { force exponent }(e) \text { are the input variables required for } \\
\text { the simulation. } \\
\text { - Input variables are determined by ECS approach } \\
\text { considering spherical bodies in contact }\end{array}$ \\
\hline
\end{tabular}




\begin{tabular}{lll}
$6 \quad$ ECS approach by RM & - & Penalty regularisation parameter and coefficient of \\
- Spherical contact & restitution (COR) are the input variables required for \\
& the simulation. \\
& $-\begin{array}{l}\text { Input variables are determined by ECS approach } \\
\text { considering spherical bodies in contact. }\end{array}$ \\
\hline
\end{tabular}

\section{EXPERIMENTAL INVESTIGATION}

An experiment is performed to validate the kinematic characteristics obtained from MBD analysis. The angular velocity of the rocker of a crank-rocker mechanism is verified with experimentation.

\section{Development of Experimental Setup of Crank-Rocker Mechanism}

The experimental setup of a crank-rocker mechanism is developed to achieve the angular speed of the rocker with respect to the crank positions at the various input speeds. It is significant because the angular speed of the rocker is a function of crank position angle. The developed experimental setup is shown in Figure 4.

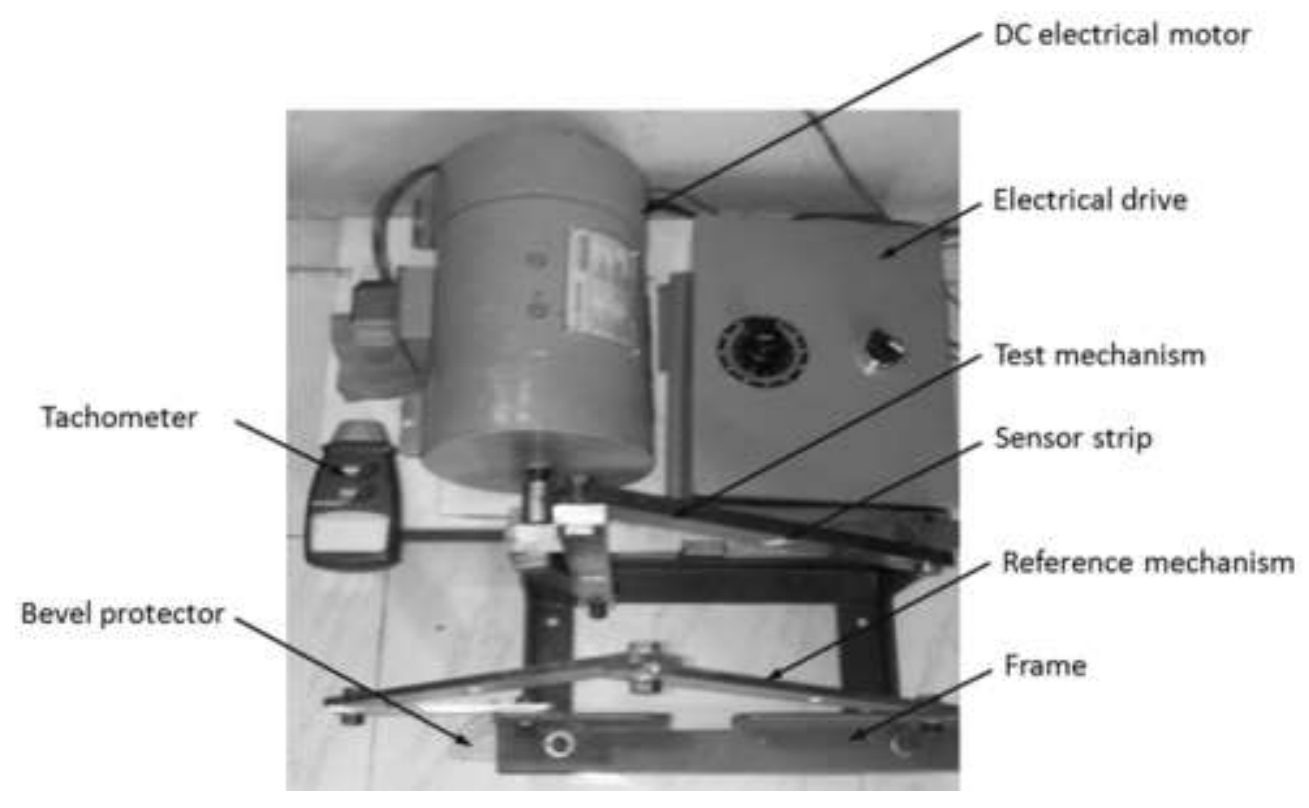

Figure 4. Experimental setup of four bar (crank-rocker) mechanism.

The crank-rocker mechanism on which experiment is performed is named as the test mechanism. Another mechanism with similar linkage parameters is mounted exactly parallel to the test mechanism. It is further referred as reference mechanism. The speeds (angular velocity) of the links of test mechanism are measured with respect to crank positions of reference mechanism. The purpose of the reference mechanism is to measure the angular speed of rocker at a particular crank position. The mechanism is fabricated with steel grade material (En-24) with coarse grade tolerance on links dimension and clearance fit of H8/g7. 
The linkage parameters are as stated in Table1. The coupler and rocker of the reference mechanism are with the hole of $15 \mathrm{~mm}$ diameter at the centre respective link as shown in Figure 5.

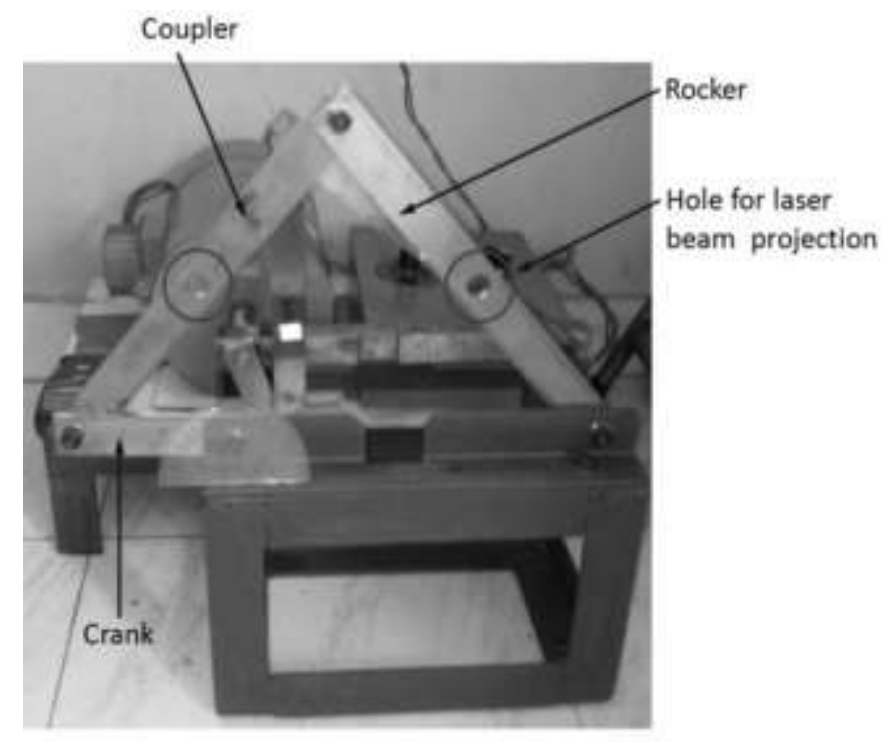

Figure 5. Provision of laser beam projection on test mechanism.

It is used to focus the laser beam on the sensor strips fixed on the links of test mechanism. A non-contact type digital laser sensor (Tachometer with accuracy $\pm 0.15 \mathrm{RPM}$ ) is used. Axial clearance of +100 microns is maintained on the length of the pin.

\section{RESULTS AND DISCUSSION}

The influence of tolerance stack on the joint forces of the four-bar mechanism has been assessed using nonlinear contact MBD analysis. The angular velocity of the rocker of crankrocker mechanism obtained from MBD analysis is verified with experimentation. The input parameters required for the analysis are determined using proposed Equivalent Contact Stiffness (ECS) approach. Angular velocity, angular acceleration of coupler and rocker, and joint forces due to the tolerance stack are investigated. These results are compared with the results of ideal crank-rocker mechanism to assess the influence of tolerance stack on the crank-rocker mechanism.

\section{Equivalent Contact Stiffness (ECS) Approach}

The damping coefficient is smaller as compared to the stiffness. Therefore, it is considered as 0.01 percent of the stiffness $[17,18]$. The hysteresis-damping factor is estimated for the proposed ECS approach and compared with the different models of damping factor proposed by Flores et.al. Lankarani and Nikravesh, Hunt and Crossley and Hybrid model of Shiwu Hu and Xinglin Guo [19]. The comparison of damping factor of different models is graphically shown in Figure 6. 


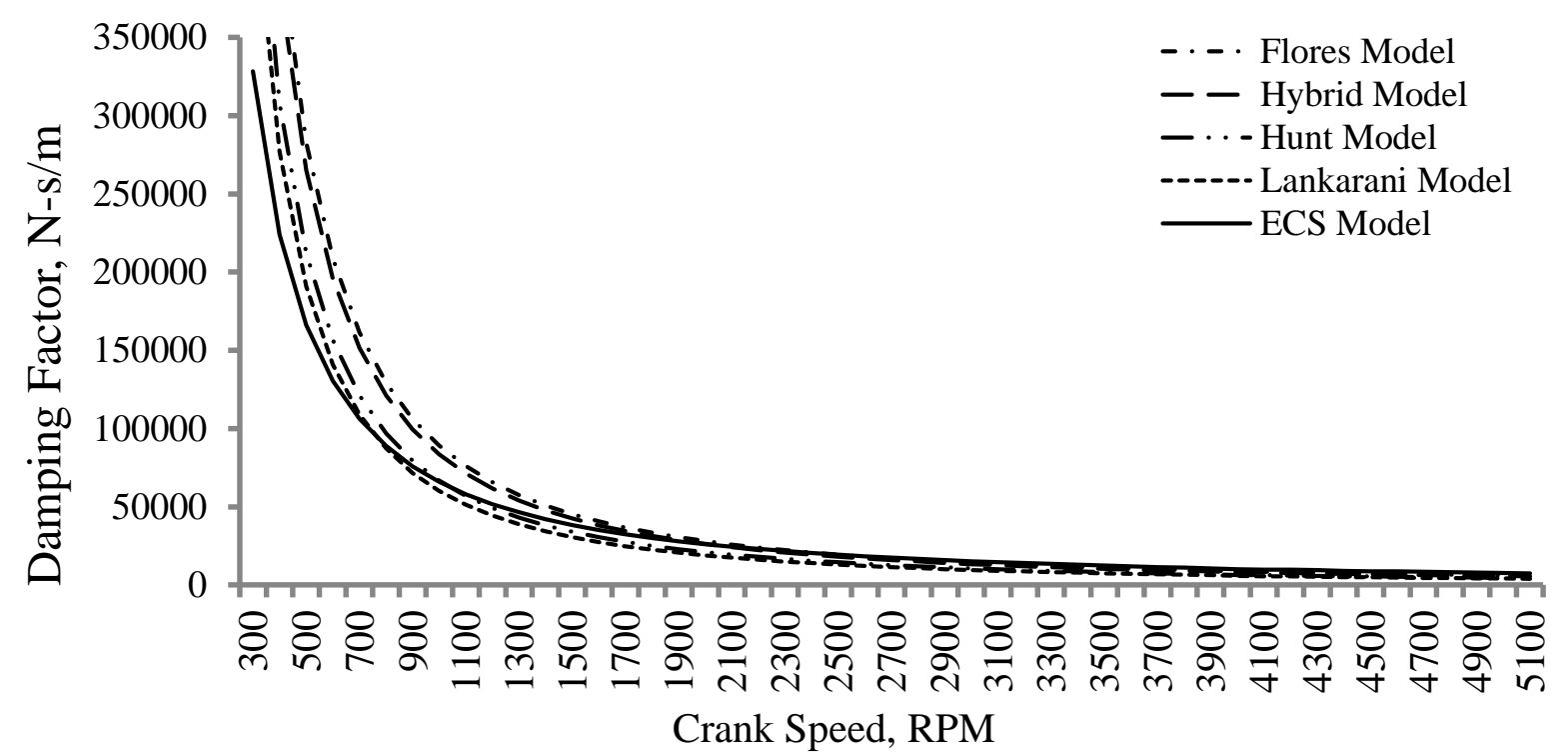

Figure 6. Comparison of hysteresis damping factor.

The nonlinear contact MBD simulation is carried out using IFM and RM with cylindrical and spherical body contact respectively. The equivalent contact stiffness and deformation of contacting bodies (bearing walls of a link and connecting pin) are increased with increase in crank speed. The hysteresis damping factor estimated for ECS model is less for the slower crank speed compared with other models. The damping factor is reduced for higher crank speed. This shows that the deformation of contacting element is increased with increase in input speed. The trend of damping factor is in agreement with trends of damping factor of above-stated models, it proved that the assumption of damping $(0.01 \%$ of the equivalent stiffness) used for the MBD analysis of the crank-rocker mechanism is appropriate.

\section{Conventional Approach of IFM}

The MBD analysis of the crank-rocker mechanism with the clearance at four revolute joints (crank-fixed link, crank-coupler, coupler-rocker, and rocker-fixed link joints) is carried out by conventional approach. One degree of freedom (DoF) joint between the pair of links is not possible due to the clearance in the joint. Therefore, it is essential to define the contact between the inner wall of bearing and the pin of the joint. The contact force is used to define the contact [17,24]. The contact parameters used as input variables for MBD analysis of selected crank-rocker mechanism are given in Table 3. 
Table 3. Contact parameters for impact force method

\begin{tabular}{lcc}
\hline \multicolumn{1}{c}{ Contact Parameters } & $\begin{array}{c}\text { Permissible } \\
\text { Range [22] }\end{array}$ & $\begin{array}{c}\text { Tuned for } \\
\text { Contact MBD } \\
\text { Analysis }\end{array}$ \\
\hline Stiffness, (N/mm) & $1 \times 10^{4}-1 \times 10^{5}$ & $1 \times 10^{4}$ \\
Force Exponent & $1.5-2.2$ & 1.5 \\
Damping, (N-s/mm) & $1-1000$ & 10 \\
Penetration Depth, (mm) & $0.01-0.1$ & 0.1 \\
\hline
\end{tabular}

In absence of experimental values of contact parameters, conventionally analysis is started with standard values of contact parameters in the permissible range $[15,18,25]$. The contact parameters are attuned according to accomplish the required motion of the mechanism links. Otherwise, for higher stiffness, deformation of the contacting bodies is less, it will affect the damping coefficient as it is a function of penetration velocity. MBD analysis of crank-rocker mechanism for input speed of 200 RPM with linkage parameters as given in Table 1 is carried out by IFM. Angular velocity plot of coupler and rocker considering ideal joints and the clearance joints is shown in Figure 7.

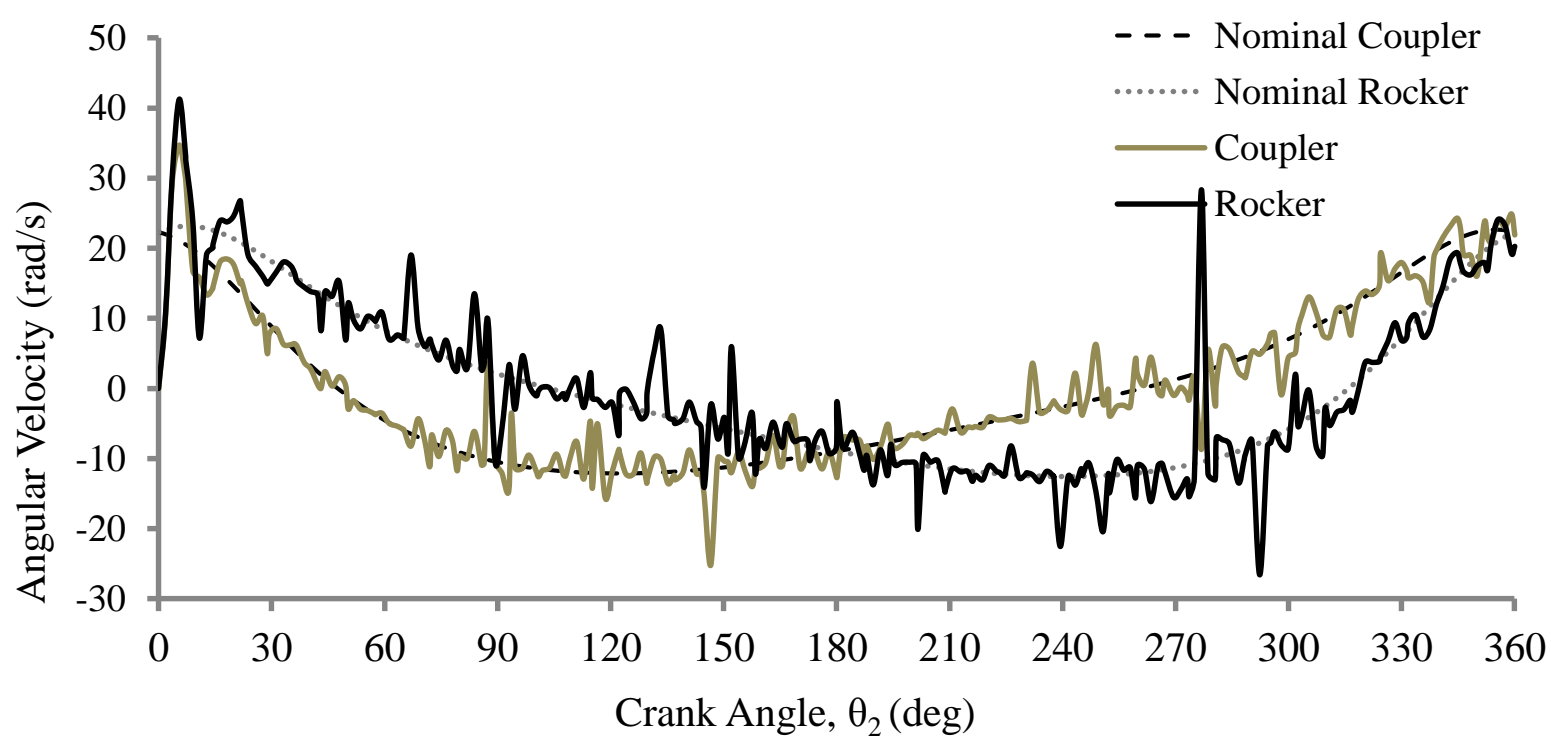

Figure 7. Angular velocity of coupler and rocker with clearance revolute joints.

An ideal or nominal mechanism is the mechnaism having all the links of nominal (basic) size without considering tolerance on it and ideal or perfect revolute joints without clearance. The mechanism considering tolerance on the link length and clearance in the joints is termed as actual mechanism. Angular velocity plots of coupler and rocker of actual mechanism are compared with ideal coupler and rocker. It is observed that at the start of motion there are high spikes in the angular velocity, it is due to the impact of joint pins inside the respective bearing walls. The behavior of the angular velocities are similar to the ideal coupler and rocker respectively. However, variations in the angular velocity are excessive, 
impractical random in nature. Therefore, an ECS approach is proposed for the estimantion of accurate contact parameters so as, the fine tuning of contact parameters and iterations of the sumlations are avoided.

Nonlinear Contact MBD Analysis of Crank-Rocker Mechanism: Input Variables Estimated by ECS Approach (Cylindrical Bodies in Contact)

The revolute joint is formed with two cylindrical bodies (pin and bearing) in contact. Therefore, the contact parameters are estimated for a constant crank speed of 200 RPM using ECS approach with two cylindrical bodies are in contact. Estimated contact parameters are given in Table 4.

Table 4. Contact parameters for selected speeds (Cylindrical Body Contact)

\begin{tabular}{cccc}
\hline $\begin{array}{c}\text { Crank Speed, } N_{2} \\
(\mathrm{RPM})\end{array}$ & $\begin{array}{c}\text { Equivalent } \\
\text { Stiffness, } K(\mathrm{~N} / \mathrm{mm})\end{array}$ & $\begin{array}{c}\text { Depth of Penetration, } \\
\delta(\mathrm{mm})\end{array}$ & $\begin{array}{c}\text { Damping, } D \\
(\mathrm{~N}-\mathrm{s} / \mathrm{mm})\end{array}$ \\
\hline 200 & 242348 & $2.69 \times 10^{-10}$ & 2423 \\
\hline
\end{tabular}

The nonlinear contact MBD analysis of crank-rocker mechanism is carried out. The angular velocity plot of coupler and rocker of the crank-rocker mechanism are given in Figure 8 .

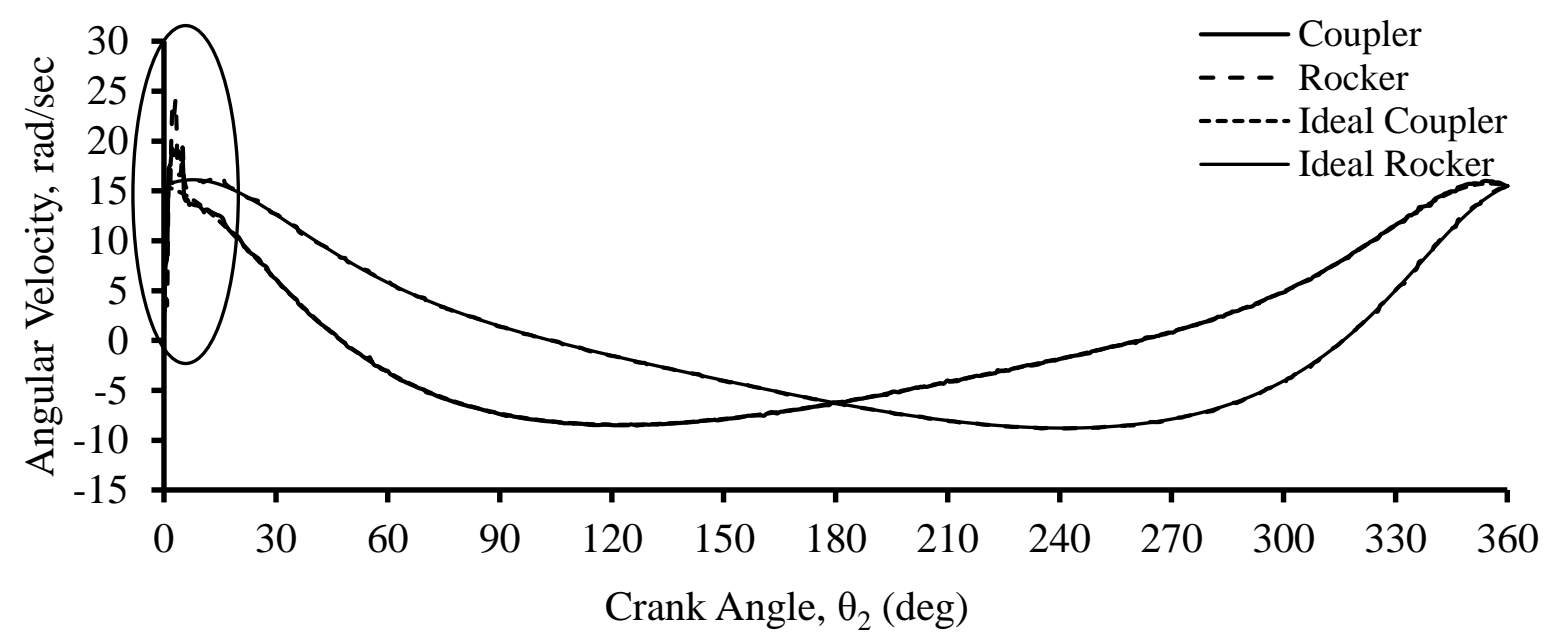

Figure 8. Angular velocity plot of coupler and rocker (with ECS approach).

Deviations are observed in the angular velocity of coupler and rocker. The deviation in the angular velocities at the initial stage of the motion is given in Figure 9. It is observed that angular velocity of the rocker at the initial stage of motion is $23.94 \mathrm{rad} / \mathrm{s}$. An angular acceleration of rocker is shown in Figure 10. 


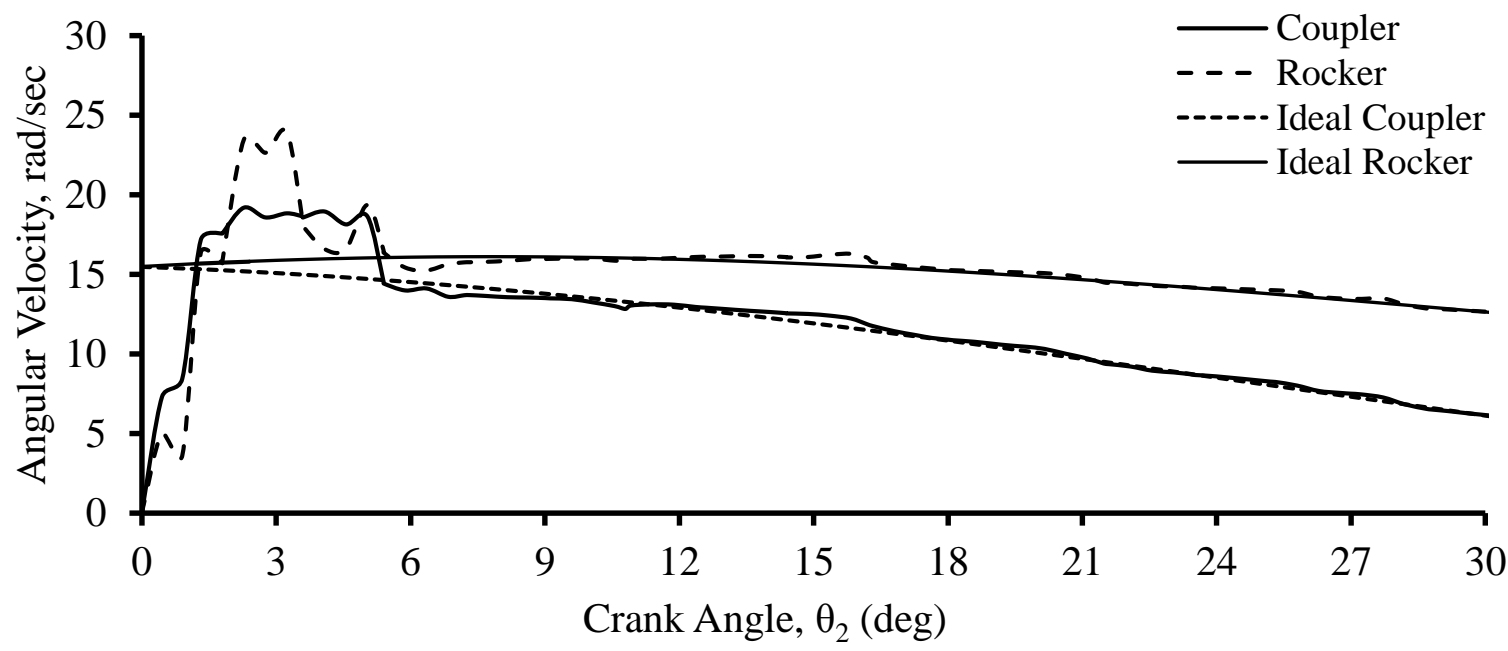

Figure 9. Angular velocity plot at initial stage of coupler and rocker

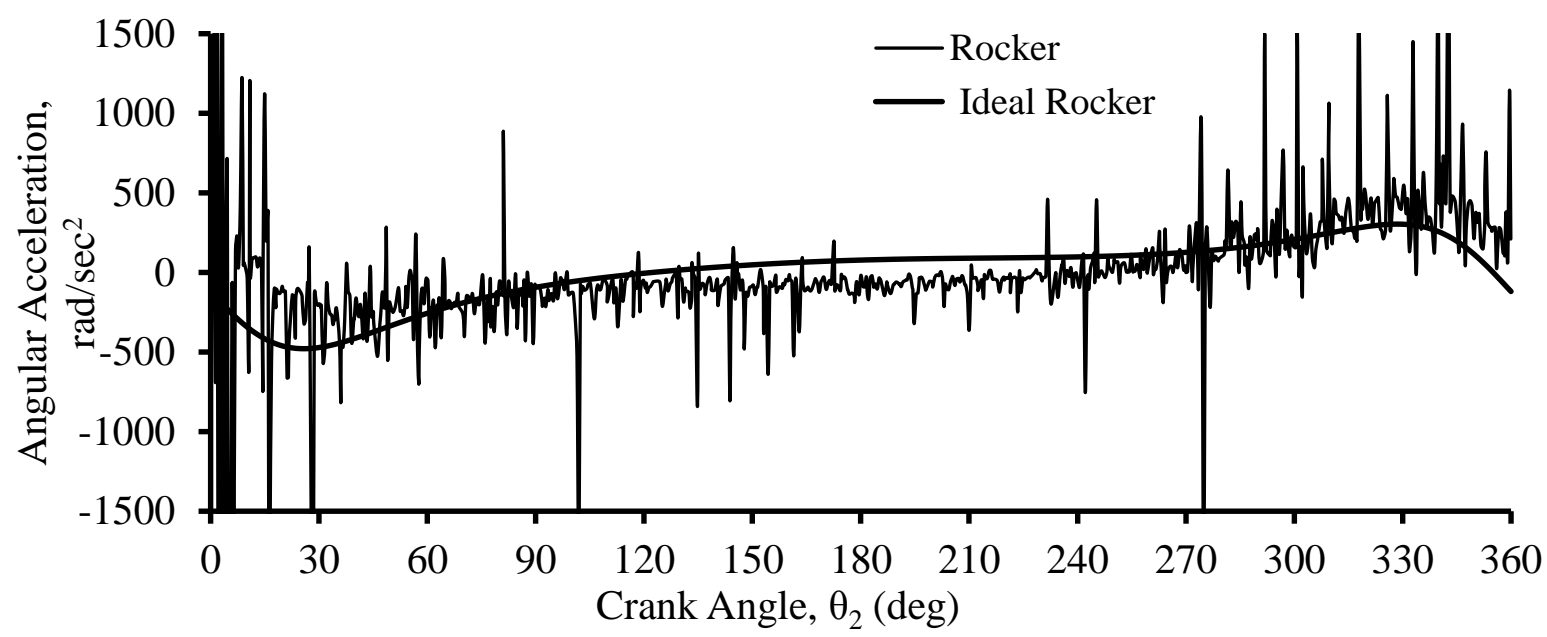

Figure 10. Angular acceleration plot of rocker with ECS approach.

It is observed that the acceleration of rocker is high and discontinuous in comparison with the acceleration of nominal rocker. It is due to the clearance in the joints. Similarly, joint forces are estimated using MBD analysis. Variations in the joint forces at the inner wall of bearing and pin, in a cycle of the crank are shown in Figure 11. 


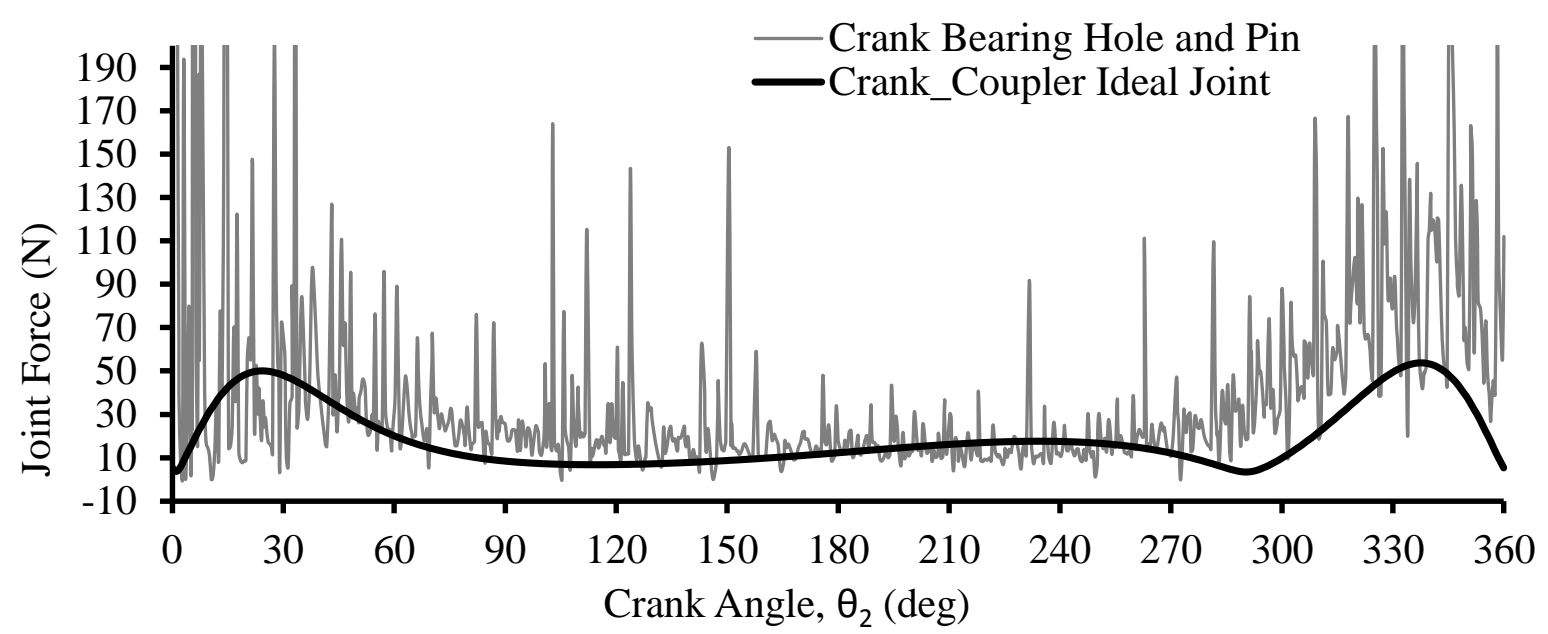

Figure 11. Joint forces at inner wall crank bearing and pin

The joint forces are high at the start of motion and continuously varying in a cycle. It is due to the impact of the pin on the inner wall of bearing.

Nonlinear Contact MBD Analysis of Crank-Rocker Mechanism: Input Variables Estimated by ECS Approach (Spherical Bodies in Contact)

The contact parameters are estimated for a constant crank speed of 200 RPM as given in Table 5.

Table 5. Contact parameters for selected speeds (Spherical Contact Method)

\begin{tabular}{cccc}
\hline $\begin{array}{c}\text { Crank Speed, } \\
N_{2}(\mathrm{RPM})\end{array}$ & $\begin{array}{c}\text { Equivalent Stiffness, } \\
K(\mathrm{~N} / \mathrm{mm})\end{array}$ & $\begin{array}{c}\text { Depth of Penetration, } \\
\delta(\mathrm{mm})\end{array}$ & $\begin{array}{c}\text { Damping, } D \\
(\mathrm{~N}-\mathrm{s} / \mathrm{mm})\end{array}$ \\
\hline 200 & 2500 & $3.67 \times 10^{-5}$ & 25.00 \\
\hline
\end{tabular}

The angular velocity of coupler and rocker is shown in the Figure 12 and Figure 13.

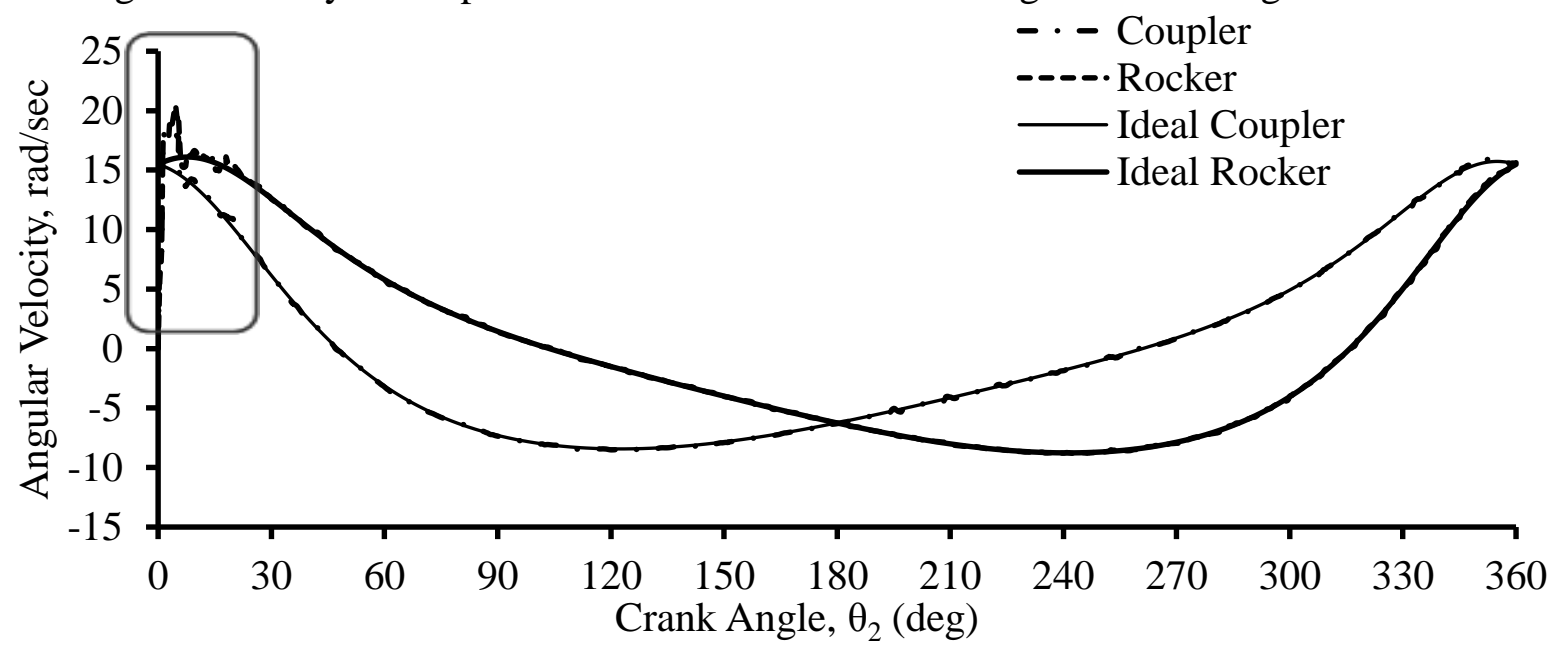

Figure 12. Angular velocity of coupler and rocker 


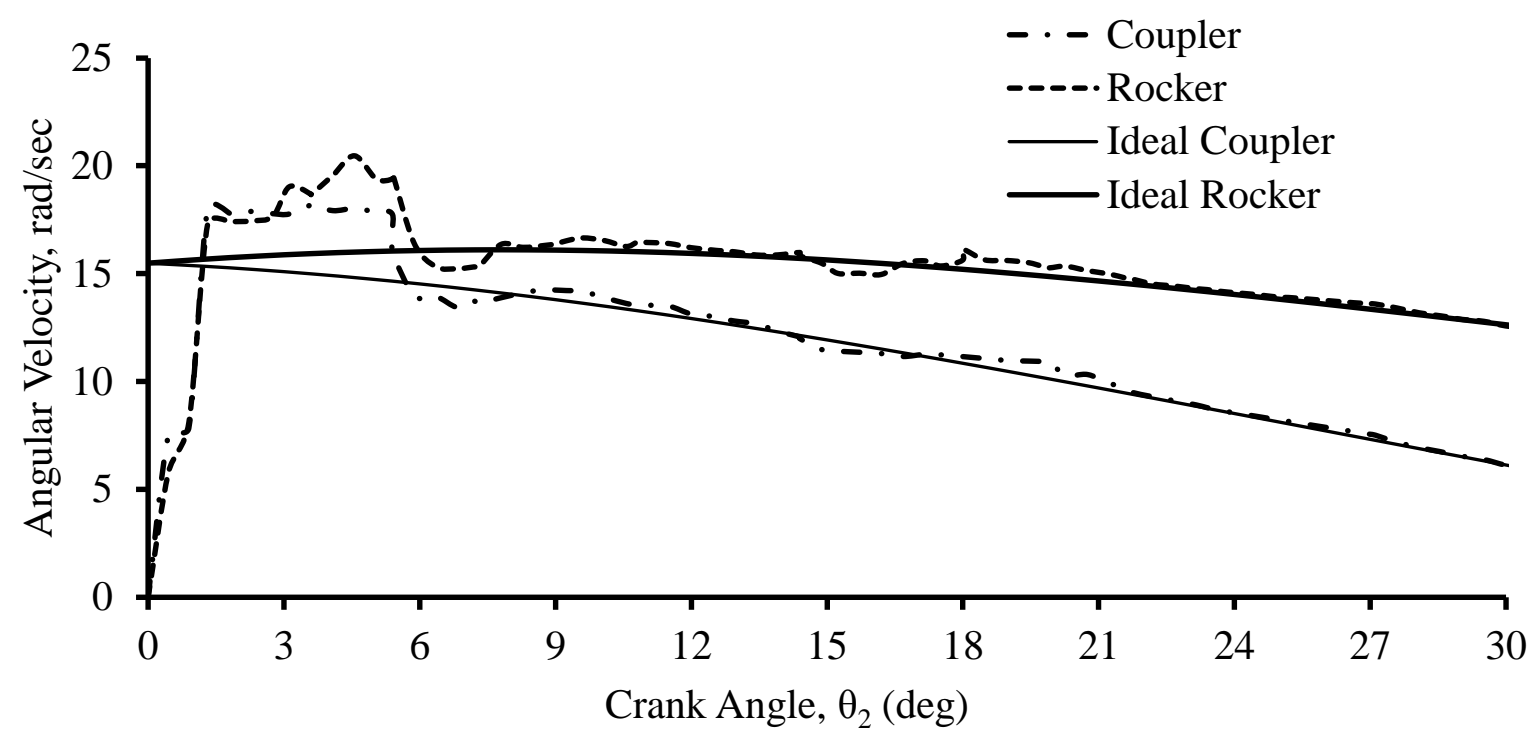

Figure 13. Angular velocity of coupler and rocker

Similarly, angular acceleration of the rocker is shown in Figure 14. The oscillations in the acceleration are higher in the initial stage of motion and are random in nature.

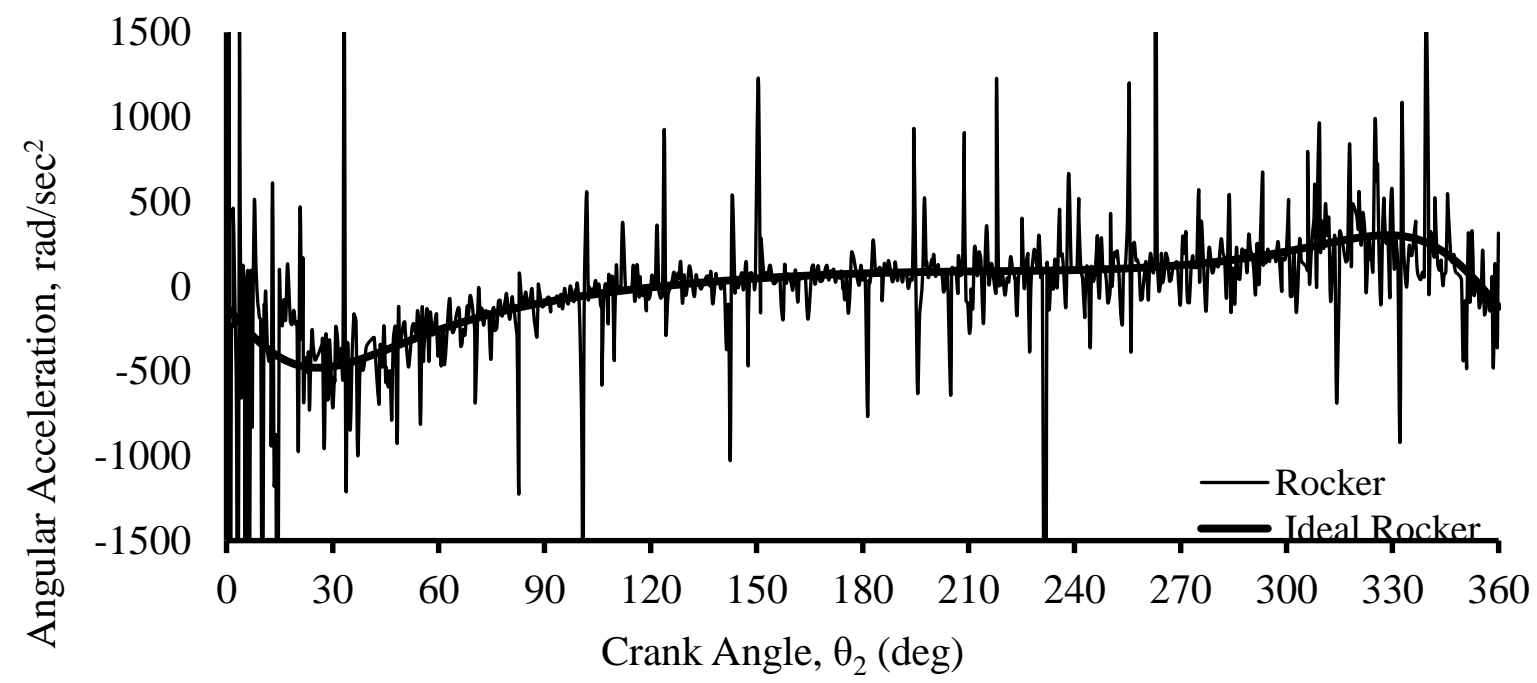

Figure 14. Angular acceleration of rocker.

The angular velocity of the nominal coupler and nominal rocker is $15.49 \mathrm{rad} / \mathrm{s}$ at the start of motion. The oscillations in the angular velocity are observed at the initial stage motion. The angular velocity of the coupler is increased to $18.21 \mathrm{rad} / \mathrm{s}$ and angular velocity of the rocker is increased to $20.46 \mathrm{rad} / \mathrm{s}$. High spikes in the angular velocity of coupler and rocker are observed between the crank position angles $0^{\circ}$ to $6^{\circ}$. The joint forces developed in the crank-coupler, coupler-rocker and rocker-fixed link are given in Table 6 . The crank bearing-pin joint and coupler bearing-pin joint of the crank-coupler revolute joint is shown in Figure 15. 


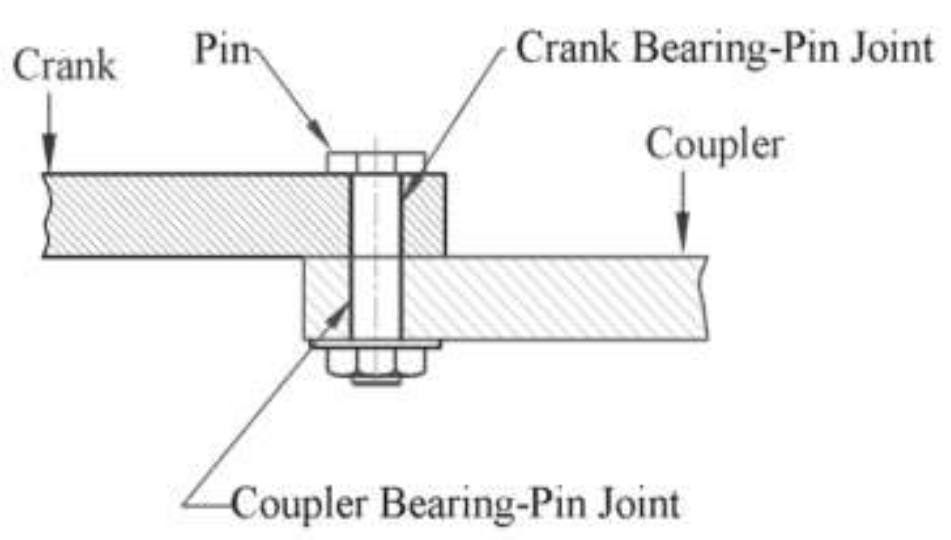

Figure 15. Components of crank-coupler revolute joint

Table 6. Joint Forces in the different joints of crank-rocker mechanism.

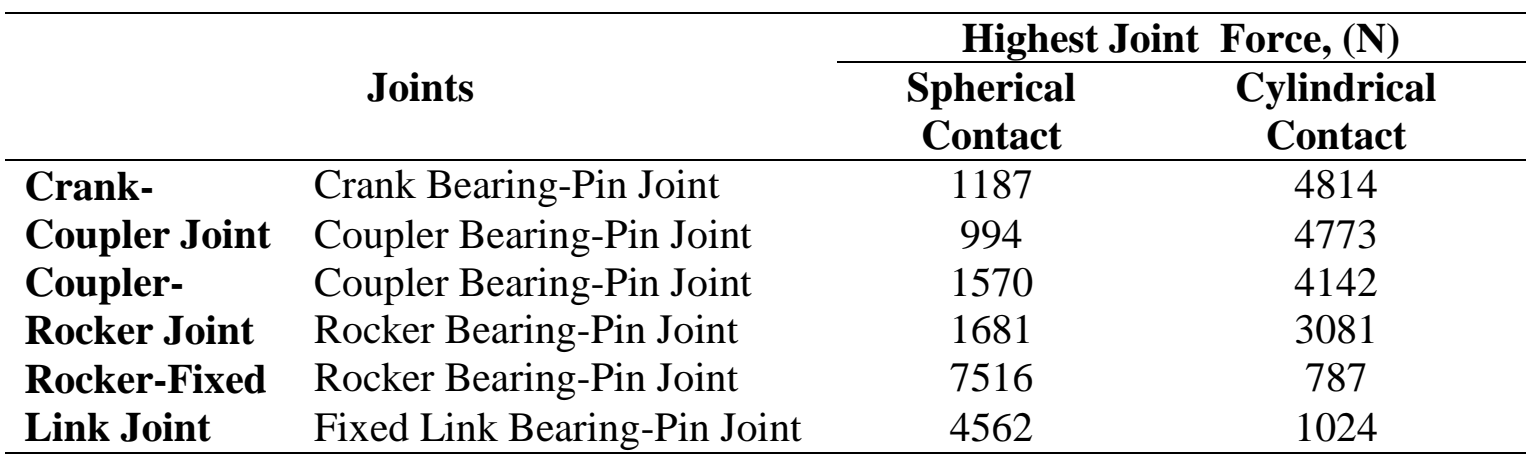

The angular velocity of coupler and rocker is estimated considering spherical body contact. The percentage increase in velocity of the coupler is $15.69 \%$ and $21.98 \%$ in spherical and cylindrical contact respectively. Similarly, the percentage increase in angular velocity rocker is $27 \%$ and $48.6 \%$ in spherical and cylindrical contact respectively. The angular accelerations are very high, 19457.5 and $13961.7 \mathrm{rad} / \mathrm{s}^{2}$ in coupler and rocker respectively at the initial stage of the motion and there are continuous oscillations in a cycle. The increase in the acceleration leads to increase in joint forces. Joint forces are estimated by nonlinear contact MBD analysis of crank-rocker mechanism. It is observed that the large variation in joint force is at the initial stage of the cycle and at the end of the cycle. The maximum instantaneous force in the crank-coupler joint is $1186.54 \mathrm{~N}$. It increases the wear in the joint and affects the accuracy of motion of the coupler. There is a significant increase in the joint forces due to the variation in the link dimensions. It has observed that the accelerations and joint forces estimated by the cylindrical contact method are very high and not practical.

The forces developed in the joints of crank-rocker mechanism for tolerance stack of $\pm 4.4 \mathrm{~mm}$ are estimated. Joint forces are higher at the crank-coupler joint when the link lengths due to tolerance are higher than nominal lengths. However, the joint forces are higher at the fixed link-rocker joint when link lengths are smaller than the nominal link lengths, although clearance in the joint is less. It is due to the reduction in effective length of mechanism linkage. 


\section{Experimental Investigation of the Angular Speed of Rocker}

Experiments are carried out on developed experimental set up of a crank-rocker mechanism. Input (crank) speed is considered 200 RPM. Rocker speed is measured for one complete rotation of crank at $30^{\circ}$ step. It has observed from Figure 17 to Figure 20 that trend of the angular speed of rocker is similar to the angular speed of nominal rocker. In the initial stage of motion, the plot of the angular velocity of nominal rocker has started from 932 RPM, whereas, it is started from zero in both MBD analysis method and experimentation. The error in the experimentation is estimated and given in Table 7.

Table 7. Angular speed of the rocker at 200 RPM crank speed

\begin{tabular}{ccccc}
\hline \multirow{2}{*}{$\begin{array}{c}\text { Sr. } \\
\text { No }\end{array}$} & $\begin{array}{c}\text { Crank Position } \\
\text { Angle (Deg) }\end{array}$ & $\begin{array}{c}\text { MBD } \\
\text { Simulation }\end{array}$ & Experimentation & Error (\%) \\
\cline { 3 - 5 } & & 932 & 927 & -0.50 \\
2 & 30 & 760 & 644 & -15.26 \\
3 & 60 & 350 & 358 & 2.29 \\
4 & 90 & 88 & 95 & 7.58 \\
5 & 120 & -90 & -91 & 1.48 \\
6 & 150 & -240 & -248 & 3.47 \\
7 & 180 & -376 & -375 & -0.18 \\
8 & 210 & -482 & -465 & -3.60 \\
9 & 240 & -526 & -554 & 5.32 \\
10 & 270 & -472 & -454 & -3.88 \\
11 & 300 & -244 & -249 & 1.91 \\
12 & 330 & 302 & 329 & 8.83 \\
13 & 360 & 932 & 929 & -0.36 \\
\hline
\end{tabular}

The measured speed of the rocker for reading number 5 to 11 has measured in positive values. However, it is considered negative due to the change in the direction of oscillation of rocker for error calculation. Error in the experimental readings has estimated $15 \%$ as shown in Figure 16.

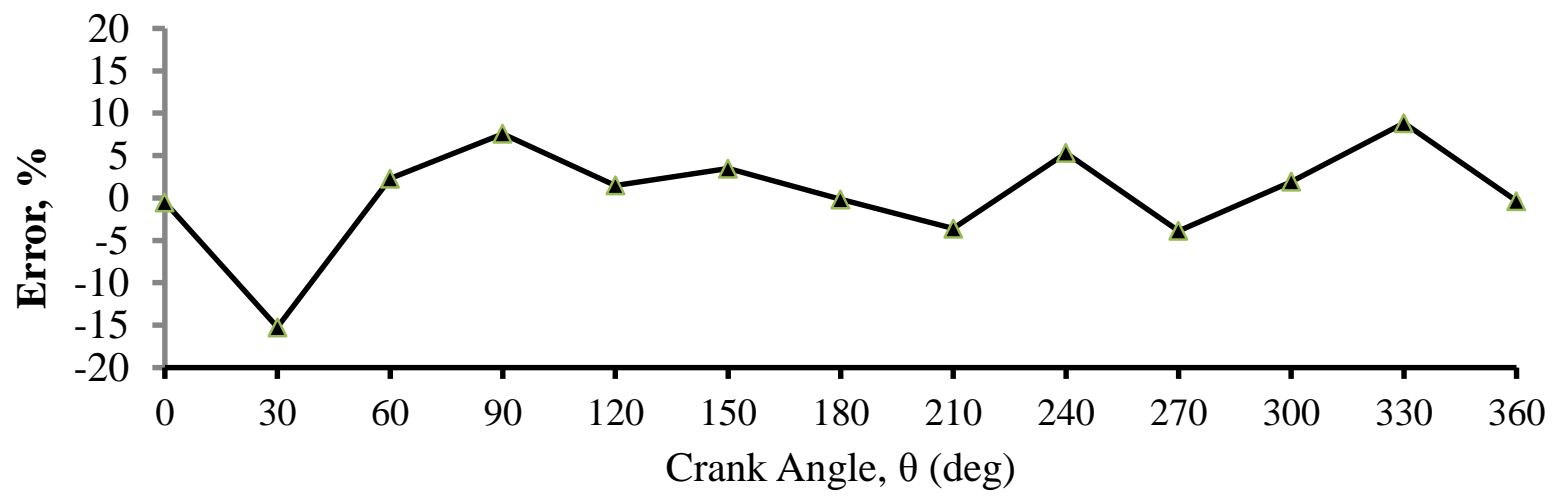

Figure16. Percentage error in numerical simulation and experimentation. 
It is due to the smaller variations in the input speed because of the voltage fluctuations and error in measurement.

\section{Correlation between Experimental and MBD Analysis Results}

Angular velocity of rocker of real mechanism obtained from contact MBD analysis is compared with measured (experimental) angular velocity of rocker. The nonlinear contact MBD analysis is carried out by four methods namely;

a) Impact Force Method with contact parameters estimated by ECS approach using spherical body contact (IFM-Spherical Contact).

b) Restitution Method with contact parameters estimated by ECS approach using spherical body contact (RM-Spherical Contact).

c) Impact Force Method with contact parameters estimated by ECS approach using cylindrical body contact (IFM-Cylindrical Contact).

d) Restitution Method with contact parameters estimated by ECS approach using cylindrical body contact (RM-Cylindrical Contact).

The results are graphically represented in Figure 17 to Figure 20.

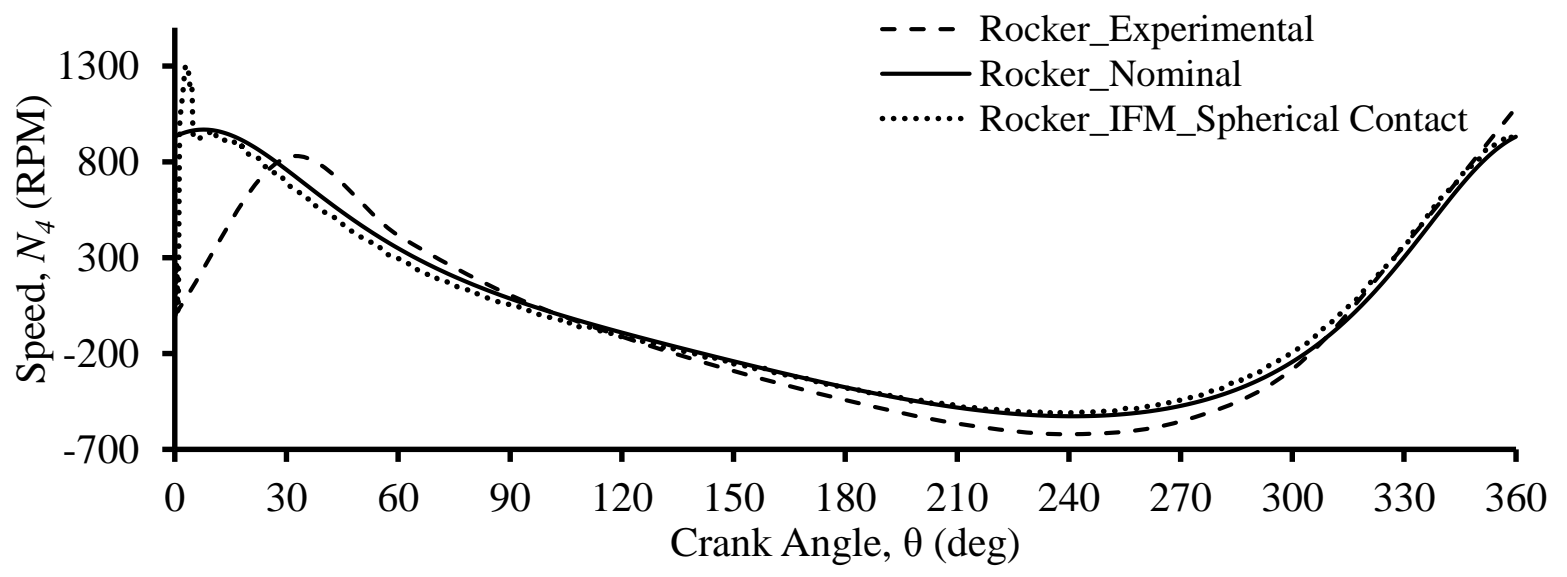

Figure 17. Angular speed of rocker (IFM-Spherical Contact)

Figure 17 shows the comparison of the angular speed of rocker in a cycle obtained from IFM. It shows that the angular speed obtained from IFM is higher (1300 RPM) at the initial stage of motion. 


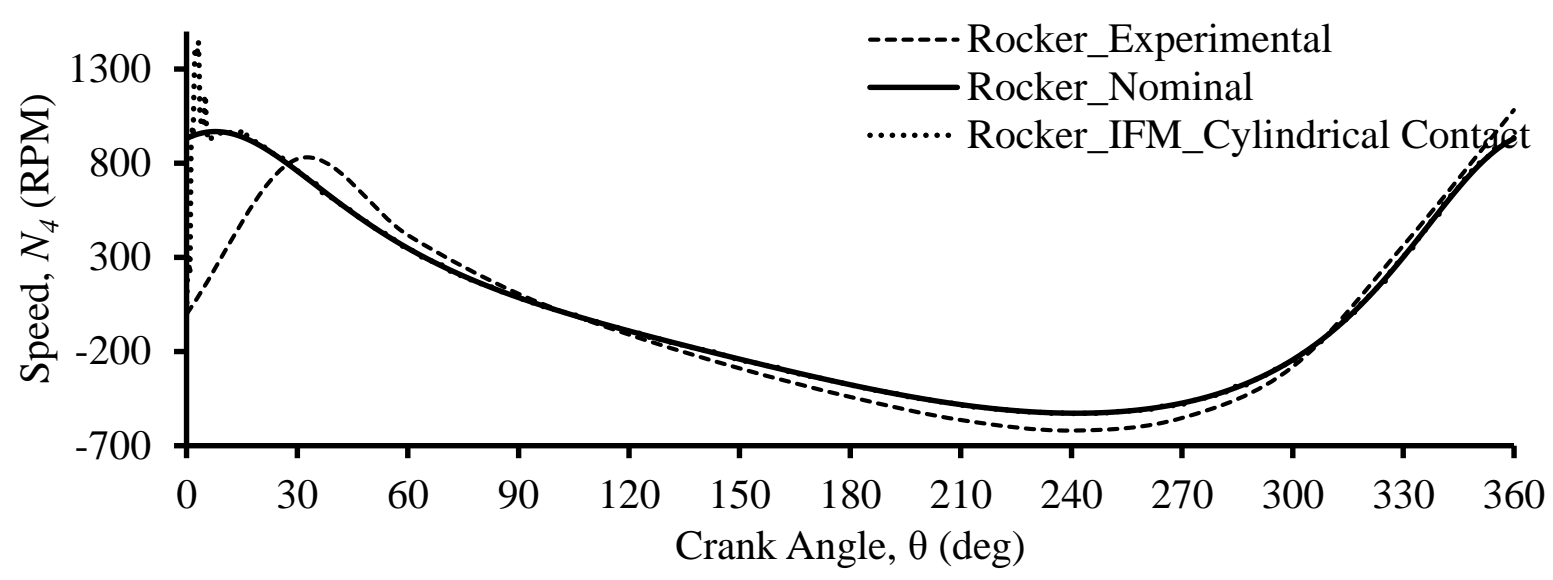

Figure 18. Angular speed of rocker (IFM-Cylindrical Contact)

Figure 19 and Figure 20 reveals that the behavior of the angular speed of rocker obtained from experimentation are with $5 \%$ variation for all four methods. Random oscillations with elevated peaks are observed in angular velocity obtained from RM

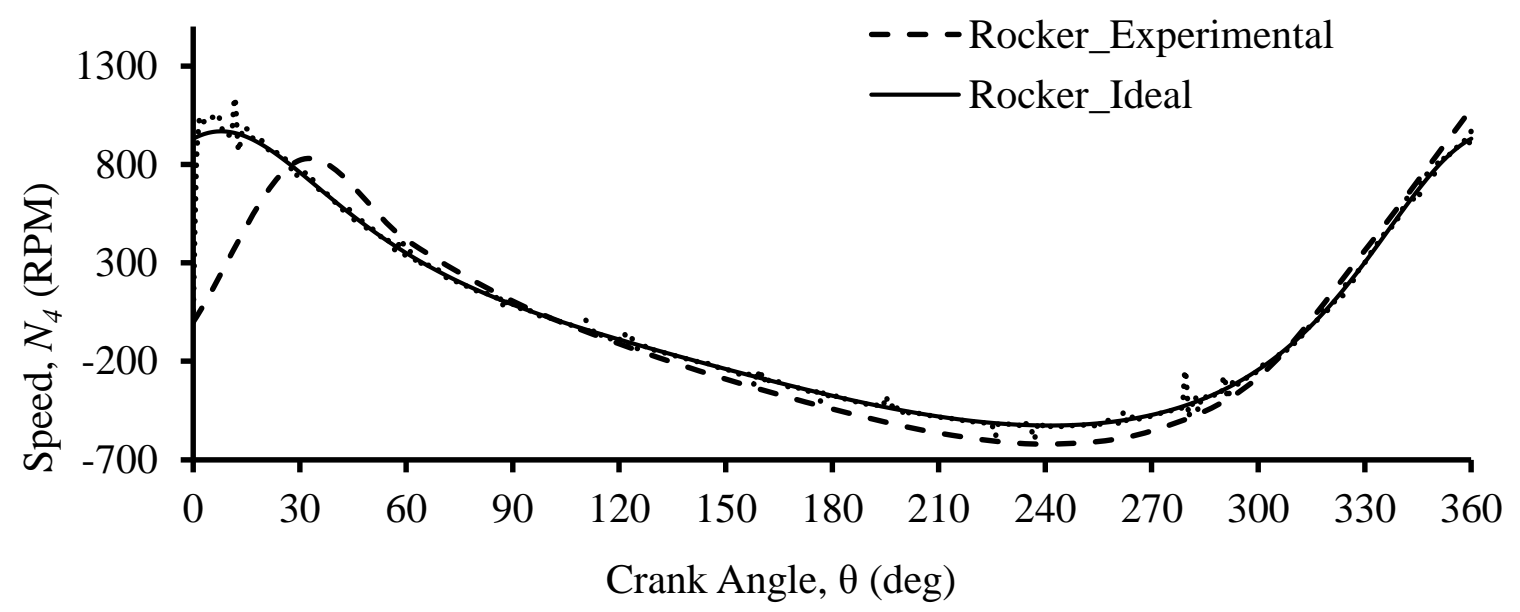

Figure 19. Angular speed of rocker (RM-Spherical Contact)

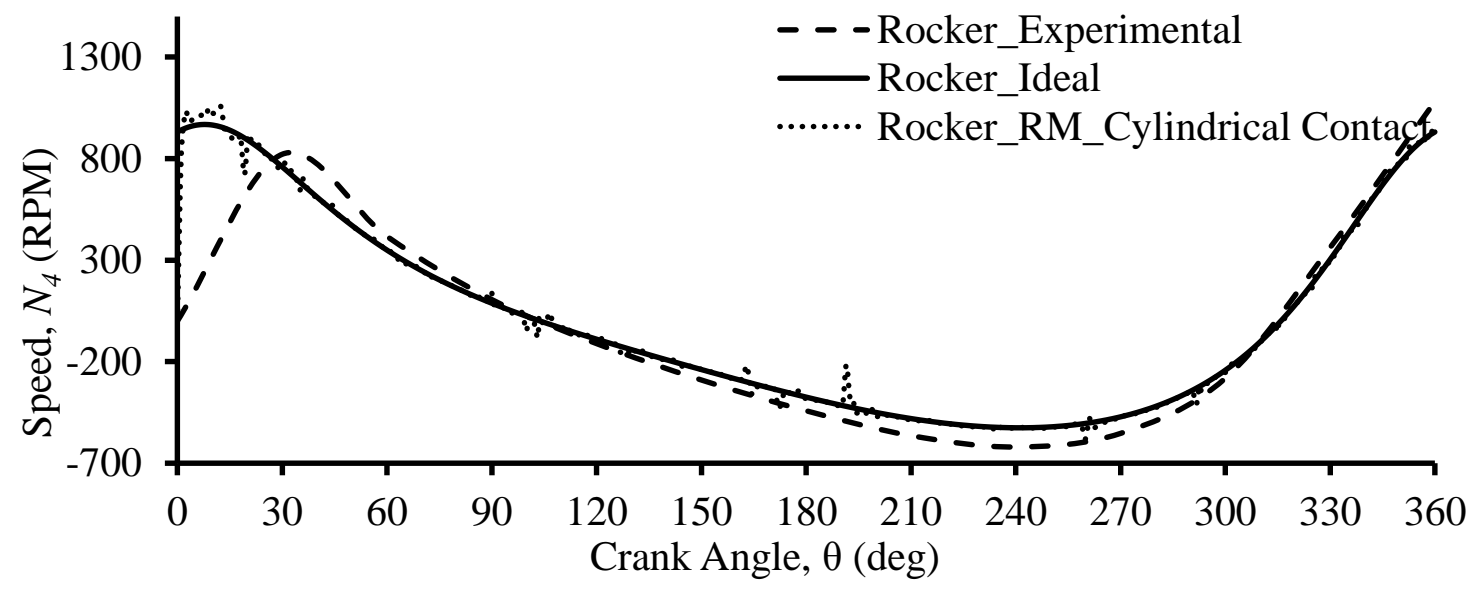

Figure 20. Angular speed of rocker (RM Cylindrical Contact) 
The angular speed of rocker obtained from IFM is in good agreement with experimental angular speed. However, the angular acceleration of coupler and the rocker and joint forces obtained from IFM-Cylindrical Contact approach are very high. Hence, the IFMSpherical Contact approach is the more accurate approach for contact MBD analysis.

\section{CONCLUSIONS}

The present work emphasizes on nonlinear contact multibody dynamic analysis of four-bar mechanism, due to tolerance stack. A methodology developed for the estimation of contact parameters for the contact MBD analysis. Exclusively, this work is on investigation of the variations of joint forces because of tolerances on the link dimensions and clearance in the multiple revolute joints of four-bar mechanism. It is concluded that the proposed ECS approach provides accurate contact parameters required for contact MBD analysis. In absence of experimental test data, an ECS approach is significant. The ECS approach has a definite advantage over existing methods is to eliminate trial substitution of contact parameters, contact parameters for combination of different geometries and material will be determined without experimentation.

The MBD analysis of crank-rocker mechanism shows that the deviation in the maximum angular acceleration of the rocker due to deviation in length of crank and fixed link is $2.7 \%$ and $1.3 \%$. The angular velocity of coupler and rocker is increased by $15.69 \%$ and $27 \%$ respectively due to tolerance stack. Therefore, precise manufacturing of crank and rocker-fixed link joint is necessary to obtain the desired mechanism performance

It is important to note that the variations in the kinematic characteristics and joint forces are increased with the tolerance grade and angular speed of crank. The oscillations of the joint forces at initial stage of motion are higher as the contacts are not stabilized during initial phase. Elevated spikes in the oscillation of joint forces indicates that at crank positions of minimum and maximum swing of rocker at which its direction of motion changes.

The experimental result of angular velocity of rocker is in conformal with analysis results. Experimental results of crank-rocker mechanism at 200 RPM crank speed show that the variation in the angular velocity of rocker is $2.65 \%$ to $4.25 \%$.

Among the four methods of nonlinear contact MBD simulation presented in this article, i.e. IFM and RM with spherical and cylindrical surface contact, the IFM with spherical body contact is more accurate when compared to the experimental results. Pose error output link (rocker), and instantaneous amplification in joint forces by virtue of tolerance stack degrade the performance of the mechanism. 


\section{REFERENCES}

[1] Yang JX, Wang JY, Anwer N, Anselmetti B. Tolerance Analysis of Parallel Mechanism with Link Dimension Deviation and Joint Clearance, 13th World Congress in Mechanism and Machine Science, Guanajuato, Mexico. 2011; 306:1-5.

[2] Bai ZF, Zhao Y. A Hybrid Contact Force Model of Revolute Joint with Clearance for Planar Mechanical Systems, International Journal of Non-Linear Mechanics. 2013;48:15-36.

[3] Flores P, Ambrósio J, Claro JCP, Lankarani HM. Dynamic Behaviour of Planar Rigid Multi-Body Systems Including Revolute Joints with Clearance, Proceedings of the Institution of Mechanical Engineers, Part K: Journal of Multi-body Dynamics, 2007;221:161-174.

[4] Flores P, Koshy CS, Lankarani HM, Ambrosio J, Claro JCP. Numerical and Experimental Investigation on Multibody Systems with Revolute Clearance Joints, Nonlinear Dynamics, 2010;65:383-398.

[5] Haroun AF, Megahed SM. Simulation and Experimentation of Multibody Mechanical Systems with Clearance Revolute Joints, International Journal of Mechanical, Aerospace, Industrial, Mechatronic and Manufacturing Engineering, 2012;6:658-667.

[6] Brutti C, Coglitore G, Valentini PP, Modeling 3D Revolute Joint with Clearance and Contact Stiffness. Nonlinear Dynamics. 2011;66:531-548.

[7] Koshy CS, Flores P, Lankarani HM. Study of the Effect of Contact Force Model on the Dynamic Response of Mechanical Systems with Dry Clearance Joints: Computational and Experimental Approaches, Nonlinear Dynamics, 2013:73:325338.

[8] Flores P, A Parametric Study on the Dynamic Response of Planar Multibody Systems with Multiple Clearance Joints. Nonlinear Dynamics. 2010;61:633-653.

[9] Bai ZF, Chen J, Sun Y. Effects of Contact Force Model on Dynamics Characteristics of Mechanical System with Revolute Clearance Joints, IJST Transactions of Mechanical Engineering, 2014:38:375-388.

[10] Flores P, Lankarani HM Dynamic Response of Multibody Systems with Multiple Clearance Joints, ASME Journal of Computational And Nonlinear Dynamics, 2012;7:3-13.

[11] Margarida M, Pedro M, Flores P, Lankarani HM, Compliant contact force models in multi-body dynamics: Evolution of the Hertz contact theory, Mechanism and Machine Theory. 2012;53:99-121.

[12] Flores P, Machado M, Silva MT, Martins JM, On the Continuous Contact Force Models for Soft Materials in Multibody Dynamics, Multibody Systems Dynamics. 2012;5:357-375.

[13] Flores P, Ambrosio J, Claro JCP, Lankarani HM. Spatial Revolute Joints with Clearances for Dynamic Analysis of Multi-Body Systems. Proceedings of the Institution of Mechanical Engineers, Part K: Journal of Multi-body Dynamics. 2006;220:257-271.

[14] Lankarani HM and Nikravesh PE. Continuous contact force models for impact analysis in multibody systems. Nonlinear Dynamics, 1994;5:193-207. 
[15] Candida MP, Ramalho AL, Ambrosio JA. Verification Process of Cylindrical Contact Force Models for Internal Contact Modeling, World Academy of Science, Engineering and Technology, 2013;7:5-25.

[16] IS 2102 (Part 1) : 1993, ISO 2768-1: 1989, General Tolerances, Part 1 Tolerances for Linear and Angular Dimensions without Individual Tolerance Indication, 2003.

[17] Alzbeta S, Gajdos L, Dekys V, Sapieta M, Analysis of the Influence of Input Function Contact Parameters of the Impact Force Process in the MSC ADAMS, Advanced Mechatronics Solutions. 2015;6:243-252.

[18] Basic ADAMS full simulation package training guide, Version 12.0, 120VIEWTR03, 2012.

[19] Hu S, Guo X. A Dissipative Contact Force Model for Impact Analysis in Multibody Dynamics, Multibody System Dynamics. 2015;35:131-151.

[20] Erdman A, Sandor G. 1991 Advanced Mechanism Design: Analysis and Synthesis Vol.1, Prentice-Hall:New Jersey.

[21] Yung C. Bearing Clearance, EASA CURRENTS, Technical Report. 2007;1-3.

[22] Muvengei M, Kihiu J, Ikua B. Effects of Clearance Size on the Dynamic Response of Planar Multi-body Systems with Differently Located Frictionless Revolute Clearance Joints, Journal of Energy Technologies and Policy, 2012;2:7-18.

[23] Akhadkar CA, Deoghare AB, Vaidya AM, Walke PV. A New Approach for Estimation of Penalty Parameter for Mechanism with Tolerance Stack-Up, International Journal of Engineering and Technology (IJET), 2016;8:129-137.

[24] Yan S, Xiang W, Zhang L. A Comprehensive Model for 3D Revolute Joints with Clearances in Mechanical Systems. Nonlinear Dynamics. 2014;59:342-359.

[25] Varedi SM, Daniali HM, Dardel M, Fathi A. Dynamic Behaviour Analysis of a Planar Four-bar Linkage with Multiple Clearances Joint, International Journal of Engineering, IJE TRANSACTIONS B: Applications. 2015;28:243-250.

[26] Varedi SM, Daniali HM, Dardel M, Fathi A, Dynamic Behaviour Analysis of a Planar Four Bar Linkage with Three Clearance Joints, Robotics and Mechatronics (ICRoM), Second RSI/ISM International Conference on Robotics and Mechatronics, Tehran. 2014:595-600.

[27] Tang Y, Chang Z, Dong X, Hu Y, Yu Z. Nonlinear Dynamics and Analysis of a FourBar Linkage with Clearance. Front Mechanical Engineering. 2013;8:160-168. 